\title{
Transient Pupil Dilation after Subsaccadic Microstimulation of Primate Frontal Eye Fields
}

\author{
Sebastian J. Lehmann ${ }^{1,3}$ and ${ }^{\circ B}$ Brian D. Corneil ${ }^{1,2,3}$ \\ Departments of ${ }^{1}$ Physiology and Pharmacology and ${ }^{2}$ Psychology, Western University, London, Ontario N6A 5B7, Canada and ${ }^{3}$ The Brain and Mind \\ Institute, Robarts Research Institute, London, Ontario N6A 5B7, Canada
}

\begin{abstract}
Pupillometry provides a simple and noninvasive index for a variety of cognitive processes, including perception, attention, task consolidation, learning, and memory. The neural substrates by which such cognitive processes influence pupil diameter remain somewhat unclear, although cortical inputs to the locus coeruleus mediating arousal are likely involved. Changes in pupil diameter also accompany covert orienting; hence the oculomotor system may provide an alternative substrate for cognitive influences on pupil diameter. Here, we show that low-level electrical microstimulation of the primate frontal eye fields (FEFs), a cortical component of the oculomotor system strongly connected to the intermediate layers of the superior colliculus (SCi), evoked robust pupil dilation even in the absence of evoked saccades. The magnitude of such dilation scaled with increases in stimulation parameters, depending strongly on the intensity and number of pulses. Although there are multiple pathways by which FEF stimulation could cause pupil dilation, the timing and profile of dilation closely resembled that evoked by SCi stimulation. Moreover, pupil dilation evoked from the FEFs increased when presumed oculomotor activity was higher at the time of stimulation. Our findings implicate the oculomotor system as a potential substrate for how cognitive processes can influence pupil diameter. We suggest that a pathway from the frontal cortex through the SCi operates in parallel with frontal inputs to arousal circuits to regulate task-dependent modulation of pupil diameter, perhaps indicative of an organization wherein one pathway assumes primacy for a given cognitive process.
\end{abstract}

Key words: frontal eye fields; monkey; oculomotor; pupil; stimulation

Significance Statement

Pupillometry (the measurement of pupil diameter) provides a simple and noninvasive index for a variety of cognitive processes, offering a biomarker that has value in both health and disease. But how do cognitive processes influence pupil diameter? Here, we show that low-level stimulation of the primate frontal eye fields can induce robust pupil dilation without saccades. Pupil dilation scaled with the number and intensity of stimulation pulses and varied with endogenous oculomotor activity at the time of stimulation. The oculomotor system therefore provides a plausible pathway by which cognitive processes may influence pupil diameter, perhaps operating in conjunction with systems regulating arousal.

\section{Introduction}

The diameter of our pupil is highly dynamic and is controlled by a balance of signaling in the autonomic nervous system (for review, see McDougal and Gamlin 2015). Pupil diameter changes with overall luminance levels, constricting in bright light and dilating in the dark. In addition, changes in pupil diameter ac-

Received Nov. 26, 2015; revised Feb. 12, 2016; accepted Feb. 25, 2016.

Author contributions: S.J.L. and B.D.C. designed research; S.J.L. performed research; S.J.L. analyzed data; S.J.L. and B.D.C. wrote the paper.

This work was supported by operating grants from the Canadian Institutes of Health Research (MOPs 93796, 123247 and 142317). We thank K. Faubert for technical and surgical support, D. Pitre for animal care, and T. Shoot for data analysis.

The authors declare no competing financial interests.

Correspondence should be addressed to Brian D. Corneil, Robarts Research Institute, London, Ontario N6A 5B7, Canada. E-mail: bcorneil@uwo.ca.

DOI:10.1523/JNEUROSCI.4264-15.2016

Copyright $\odot 2016$ the authors $\quad 0270-6474 / 16 / 363765-12 \$ 15.00 / 0$ company a diverse range of cognitive processes such as target detection (Einhäuser et al., 2008; Privitera et al., 2010), visuospatial attention (Naber et al., 2013; Hartmann and Fischer, 2014), decision making (Einhäuser et al., 2010; de Gee et al., 2014), memorization (Papesh et al., 2012), learning (Eldar et al., 2013), performing mental calculations (Ahern and Beatty, 1979), and task consolidation to prepare for a prosaccade or antisaccade (Wang et al., 2015). Although pupillometry can therefore provide a noninvasive proxy for many cognitive processes, the neural substrates by which cortical processes influence pupil diameter remain unclear.

One possible link between cognition and pupil diameter is systems regulating arousal, which is mediated in part by the noradrenergic locus coeruleus (LC), a major neuromodulatory system that projects widely throughout the cortex (Aston-Jones and Cohen, 2005; Sara and Bouret, 2012). Although it remains un- 
clear whether the tight relationship between LC activity and pupil diameter arises due to LC input into autonomic circuits (Szabadi, 2012; Wang and Munoz, 2015) or from a common input such as the nucleus paragigantocellularis (PGi) to both the LC and autonomic circuits (Nieuwenhuis et al., 2011; Sara and Bouret, 2012), pupil diameter is often used as a proxy for LC activity (Gilzenrat et al., 2010). In support of this, two recent studies in primates directly linked LC activity to pupillary changes (Varazzani et al., 2015; Joshi et al., 2016). Both the PGi and LC receive direct input from prefrontal areas such as the anterior cingulate cortex (ACC; Arnsten and Goldman-Rakic, 1984; Sara and Hervé-Minvielle, 1995; Aston-Jones and Cohen, 2005); hence, prefrontal influences routed through the PGi and LC provide one plausible substrate for how cognitive processes can influence pupil diameter.

In addition, pupil dilation has long been recognized as a component of the orienting response (Sokolov, 1963; for review, see Corneil and Munoz, 2014). Could the oculomotor system, which controls orienting, also provide a substrate for how cognitive processes influence pupil diameter? In support of this, the pupil dilates following presentation of salient visual or auditory stimuli (Wang and Munoz, 2014), and low-level microstimulation of the intermediate layers of the superior colliculus (SCi) in primates or homologous avian optic tectum can evoke pupil dilation without evoking saccades (Netser et al., 2010; Wang et al., 2012; Joshi et al., 2016). Such responses could be mediated by direct projections from the SCi to the mesencephalic cuneiform nucleus or to the parasympathetic Edinger-Westphal nucleus, or via indirect projections through the central mesencephalic reticular formation (Huerta and Harting, 1984; Dean et al., 1989; Korte et al., 1992; May, 2006; May et al., 2015). What remains unknown is whether cortical input to the SCi can evoke pupil dilation.

To address this question, we measured pupil dilation following electrical microstimulation of the primate frontal eye fields (FEFs). The FEFs are heavily interconnected with the SCi and implicated in the generation and top-down cognitive control of saccadic eye movements (for review, see Schall, 2015). FEF activity has been related to many cognitive processes associated with pupillary changes, such as task consolidation (Everling and $\mathrm{Mu}-$ noz, 2000), visuospatial attention (Gregoriou et al., 2014), and decision making (Schall and Bichot, 1998; Gold and Shadlen, 2000; Costello et al., 2013). Stimulation of the FEFs above a threshold current evokes site-specific saccades (Bruce et al., 1985). Stimulation below this threshold can elicit various nonsaccadic components of the orienting response, such as deployment of visuospatial attention (Moore and Fallah, 2001), neck muscle recruitment (Corneil et al., 2010), or widespread modulation of higher-order visual areas (Ekstrom et al., 2008). Here, we demonstrate that subsaccadic microstimulation of the FEFs evokes pupil dilation, doing so in a manner that strongly resembles that evoked from the SCi, and varies with presumed endogenous activity in the oculomotor system at stimulation onset.

\section{Materials and Methods}

Experimental setup. Experiments were performed on two male rhesus monkeys (Macaca mulatta; Animals C and S; weight, 12 and $13 \mathrm{~kg}$, respectively). All training, surgical, and experimental procedures were conducted in accordance with the regulations the Canadian Council on Animal Care policy on the use of laboratory animals and approved by the Animal Use Subcommittee of the University of Western Ontario Council on Animal Care. The monkeys' weight was constantly monitored, and their health condition was under close supervision of the university veterinarians.

Many of the surgical and experimental techniques have been published previously (Elsley et al., 2007). A cylindrical recording chamber was implanted over the right frontal lobe, allowing access to the FEFs.
Monkeys were trained to sit upright in a primate chair with their head fixed, facing an array with LEDs, radially arranged around a central fixation LED at eye level. Eye position and pupil size of the left eye were monitored with an optical infrared eye-tracking system (ETL-200, IScan) at a frequency of $240 \mathrm{~Hz}$. Pupil diameter data were converted from arbitrary units after measurements of various sized artificial pupils, printed on paper and placed in the same position as the animal's eye (resolution, $\sim 0.01 \mathrm{~mm}$ ), and normalized to baseline. For all analyses, we refer to relative changes instead of absolute values. For the majority of our analyses we exclusively used pupil measurements of the eye during stable fixation, as pupil size can be distorted by the gaze angle.

All stimulus parameters and assessment of eye position relative to computer-controlled windows were controlled in LabVIEW Realtime at a frequency of $1000 \mathrm{~Hz}$ using custom-written software that interfaced with the hardware through a National Instruments PXI controller.

Microstimulation. Intracortical microstimulation (ICMS) was induced by a stimulator and two constant-current stimulus isolation units (GrassS88 and PSIU-6, Grass Instruments) and delivered via a tungsten microelectrode (FHC). The electrode was lowered with a hydraulic microdrive (Narishige Instruments). Stimulation consisted of biphasic pulses $(0.3$ ms per phase, cathodal first). Stimulation frequency and current were controlled through the Grass S88 stimulator, whereas stimulation duration was controlled via software.

Behavioral task. The task was designed to not include a cognitive component around time of stimulation to ensure that evoked pupil responses were not confounded by task demands. Monkeys were trained to perform a gap saccade task with a long and variable fixation epoch (ranging from 1600 to $2400 \mathrm{~ms}$ ) under constant light conditions (background luminance, $1 \mathrm{~cd} / \mathrm{m}^{2}$; luminance of red fixation and target LEDs, 16.5 $\left.\mathrm{cd} / \mathrm{m}^{2}\right)$. After a gap period of $200 \mathrm{~ms}$, a saccade target appeared in one of eight different radial angles (at $0,45,90,135,180,225,270$, and $315^{\circ}$ ) at an eccentricity of $10^{\circ}$ visual angle from the fixation spot. After successful completion of a saccade, monkeys were rewarded with water at the end of a trial. In $50 \%$ of the trials (pseudorandomly interleaved), microstimulation was applied after a variable time of 800 to $1600 \mathrm{~ms}$. This long prestimulation interval ensured that pupil diameter had stabilized when stimulation was applied. After stimulation, monkeys maintained fixation for another $600 \mathrm{~ms}$ before executing the saccade (Fig. 1A). The fixation window radius ranged between 1.5 and $5^{\circ}$ (Animal S, usually 3 to $5^{\circ}$; Animal C, 1.5 to $3^{\circ}$ ); target window radius was $5^{\circ}$. The bigger fixation window for Animal S was necessary due to inconsistent fixation behavior. As shown below, we controlled for potential influence of small saccades on pupil dilation offline. Monkeys could successfully complete stimulation trials even if stimulation evoked a saccade, provided they returned to the fixation window.

For each stimulation site in FEFs, we first found the site's unique saccade threshold, i.e., the amount of current needed to evoke contralateral saccades in $\sim 50 \%$ of the trials (with $200 \mathrm{~ms}$ stimulation at $300 \mathrm{~Hz}$ ). Based on this threshold, we recorded blocks of five different stimulation levels for each site (each block with 30-50 stimulation and 30-50 nonstimulation trials), attempting to define a response curve expressing the percentage of evoked saccades versus stimulation parameter that ranged between $20-80 \%$. The order of stimulation levels across blocks was varied across days. Only sites where the average percentage of evoked saccades across levels 2 to 4 exceeded $30 \%$ were included as FEF sites.

In most of our data, we varied stimulation current, keeping frequency $(300 \mathrm{~Hz})$ and duration $(200 \mathrm{~ms})$ fixed. We also recorded a smaller subset of data where we varied either stimulation duration $(30,70,100,135$ and $165 \mathrm{~ms}$, combined with a fixed frequency of $300 \mathrm{~Hz}$ and site-specific threshold currents) or stimulation frequency $(50,100,150,200$, or 250 $\mathrm{Hz}$, combined with a fixed duration of $200 \mathrm{~ms}$ and site-specific threshold current). For these smaller subsets, the parameter levels were chosen so that variations in either frequency or duration delivered 10,20,30, 40 or 50 individual stimulation pulses.

Data analysis. All analysis was performed offline using customwritten scripts in Matlab (Mathworks). All trials with eyeblinks within the fixation epoch were removed from the database. Onset and offset of evoked saccades were detected by applying a velocity crite- 
A

Fixation epoch

Gap

Target onset

Saccade

\section{Eye}

Target

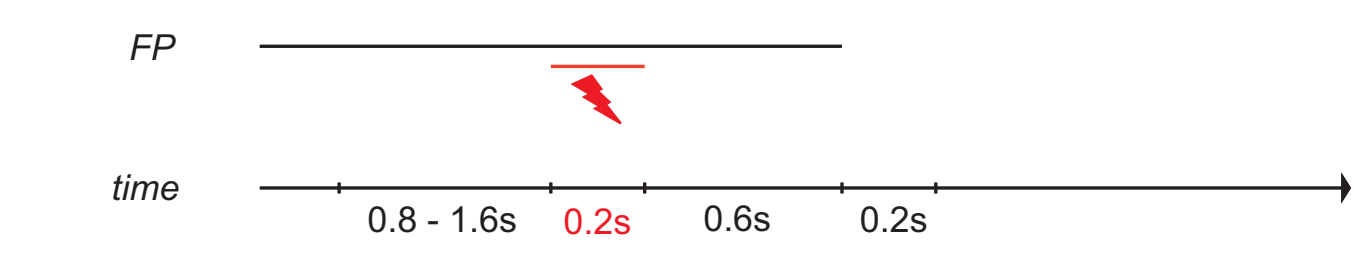

B

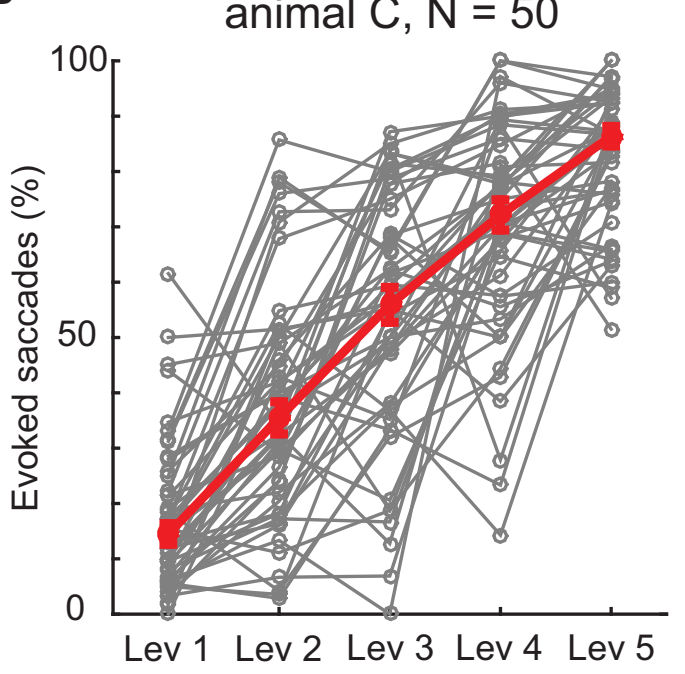

Current $(\mu \mathrm{A}) 14+/-1 \quad 18+/-1 \quad 22+/-2 \quad 27+/-2 \quad 31+/-2$

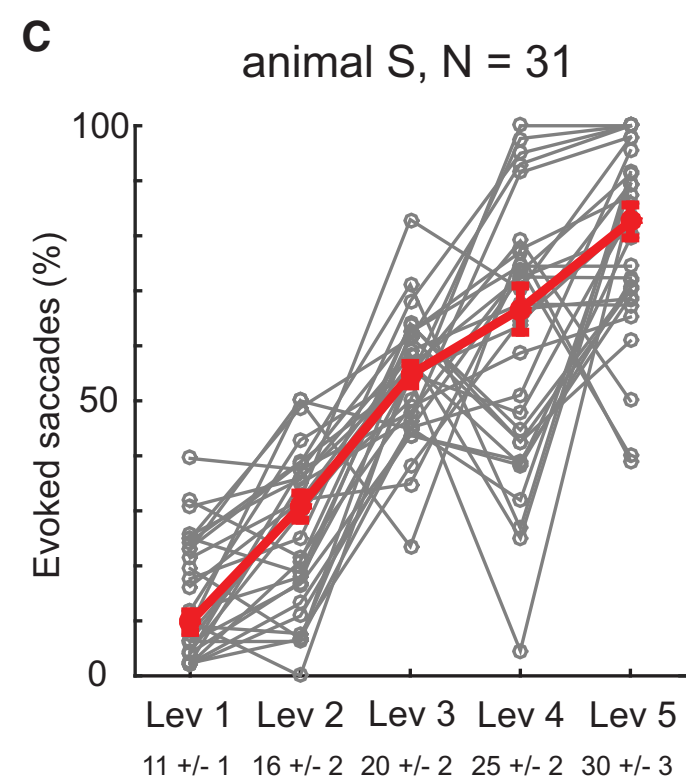

Figure 1. Behavioral task and response curves. A, Gap saccade paradigm. Subjects had to keep fixation for 1.6 to $2.4 \mathrm{~s}$, followed by a gap period of $200 \mathrm{~ms}$, before executing a saccade to a peripheral target. FEF microstimulation was applied on half of all trials after a variable fixation time. $\boldsymbol{B}, \boldsymbol{C}$, Response curves for both animals. Gray lines represent the percentage of microstimulationevoked saccades for each site and stimulation level; red curves show the average across sites (error bars indicate the SE). The average absolute current intensity at each level (with SE) is provided beneath the $x$-axis.

rion $(50 \%)$. In trials in which stimulation did not evoke a saccade, all trials with a deviation of $>1.5^{\circ}$ from initial fixation position were excluded from the database.

Trials were aligned to the onset of stimulation, or, in nonstimulation trials, to a time where stimulation would have been applied. Changes in pupil diameter were measured as the difference between the maximal pupil diameter in a certain response window (300-500 $\mathrm{ms}$ after stimulation onset) and a baseline window (averaged across the $100 \mathrm{~ms}$ before stimulation onset). For each site and stimulation level, we first defined the local maximum of the averaged pupil trials in the response window and then, for each trial separately, calculated the differences for the pupil diameter at peak time and the mean baseline. This was done for both subthreshold stimulation trials as well as for control trials; the differences between response and baseline windows were then used to perform further statistical analysis.

\section{Results}

Two macaque monkeys performed a saccade task with a long and variable fixation epoch (Fig. $1 A$ ). In our primary data set, FEF microstimulation was delivered on $50 \%$ of the trials during fixation to a total of 81 sites, with stimulation current varied across five blocks of trials at each site.
FEF microstimulation evoked contralateral gaze shifts in all 81 sites (50 sites in Animal C, 31 sites in Animal S). At the highest current in each block, the metrics of the site-specific saccade ranged between 2 and $19^{\circ}$ in radial magnitude (with a mean of $\left.7.7 \pm 3.9^{\circ} \mathrm{SD}\right)$, and $+96^{\circ}$ to $+250^{\circ}$ in radial direction $\left(179 \pm 41^{\circ}\right.$; all values given as counterclockwise rotation from straight right). Figure 1, $B$ and $C$, shows the response curves contrasting percentage of evoked saccades versus current for each of the stimulation sites. For both animals, the percentage of evoked saccades clearly increased with higher current intensities, ranging from $\sim 10 \%$ evoked saccades at the lowest stimulation level to $80 \%$ evoked saccades at highest level. The averaged applied current intensity at the highest stimulation level was around $30 \mu \mathrm{A}$ in both animals (absolute current levels are listed in Fig. $1 B, C$ ). The saccade threshold, which we define as the current at which saccades were evoked on half of all stimulation trials, was below $25 \mu \mathrm{A}$ in both animals. These threshold currents are well within the range of previous studies of the FEFs using acute electrodes (Bruce et al., 1985; Moore and Fallah, 2001; Corneil et al., 2010), particularly when one considers that stimulation in our task was being passed during active fixation, which raises saccade thresholds (Opris et al., 2001). 
A

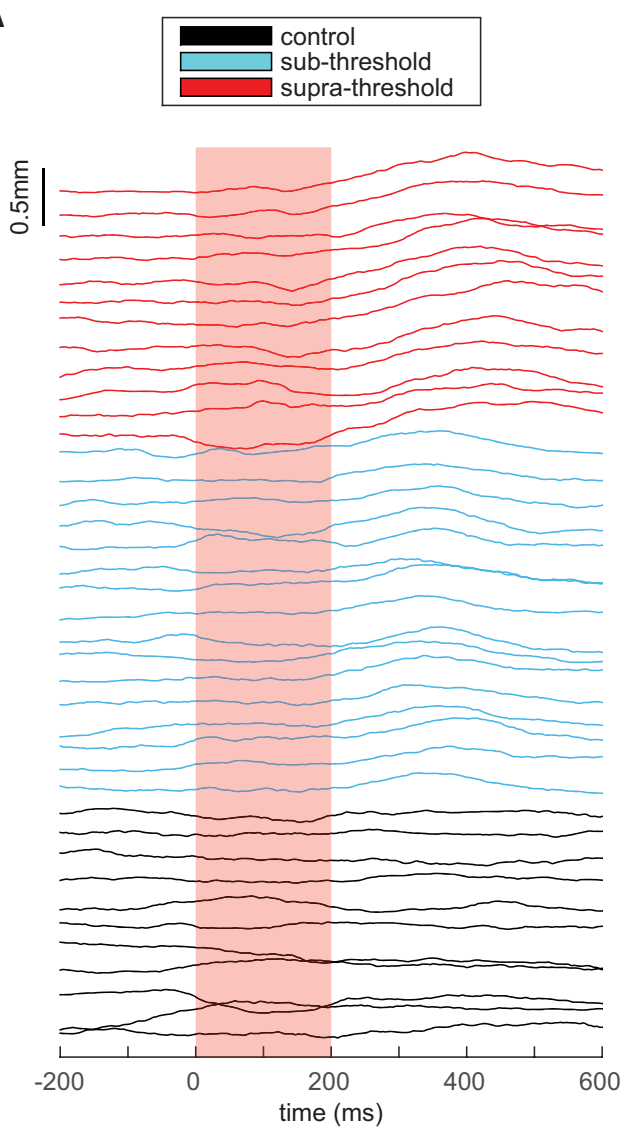

B

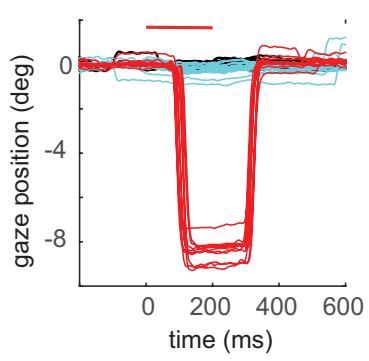

C

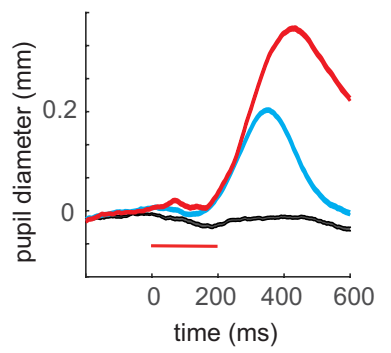

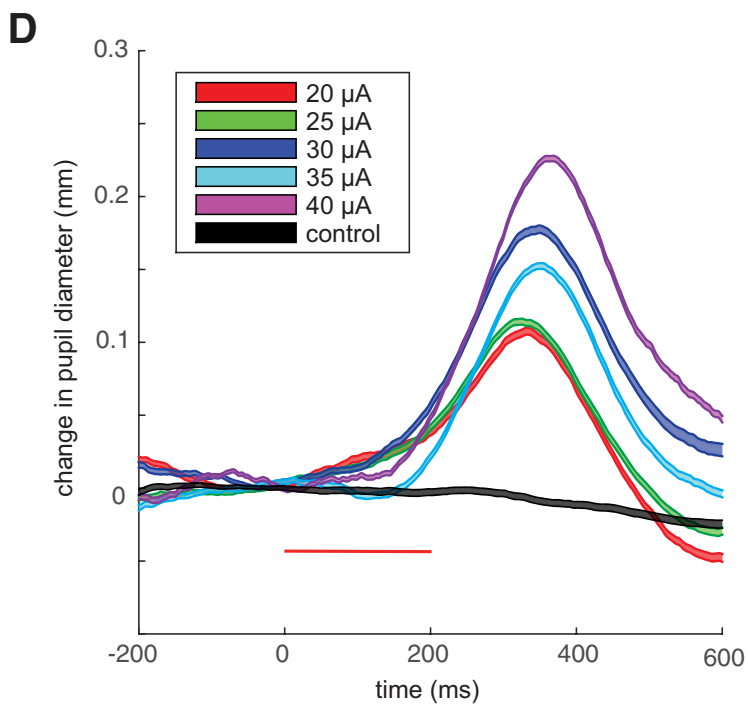

Figure 2. Evoked responses for a representative site. $\boldsymbol{A}$, Pupil diameter through time for different trial types from a representative site, segregated and staggered vertically so as to not overlap. Pupil diameter is shown for control trials (black) and stimulation trials either associated with (red) or not associated with (blue) an evoked saccade. Stimulation was $35 \mu \mathrm{A}$ at $300 \mathrm{~Hz}$ for $200 \mathrm{~ms}$ (red box indicates stimulation duration). $\boldsymbol{B}$, Horizontal eye position for the corresponding trials presented in $\boldsymbol{A}$. Suprathreshold trials consisted of evoked saccades $\sim 8^{\circ}$ to the left. $\boldsymbol{C}$, Change in pupil diameter, averaged across the different trial types shown in $\boldsymbol{A}$ (curve width indicates the SE). $\boldsymbol{D}$, Change in pupil diameter for five different current stimulation intensities applied to the same site, compared to control (black). The color code indicates the different currents (20 to $40 \mu \mathrm{A}$, in steps of $5 \mu \mathrm{A})$. Horizontal red bars in $\boldsymbol{B}-\boldsymbol{D}$ indicate stimulation time.

\section{Subsaccadic microstimulation of FEFs evokes pupil dilation}

In addition to evoking saccades, microstimulation of FEFs also induced pupil dilation. Figure $2 A$ shows the pupil dynamics for 39 individual trials recorded from Animal C; the corresponding horizontal gaze positions for these trials are depicted in Figure $2 B$. In this particular example, stimulation was set to $35 \mu \mathrm{A}$ at $300 \mathrm{~Hz}$ for $200 \mathrm{~ms}$. The types of trials are segregated into control trials without stimulation (black), stimulation trials with an evoked saccade (red, termed "suprathreshold" trials), and stimulation trials without an evoked saccade (blue, termed "subthreshold" trials). All trials are aligned to stimulation onset (or when stimulation would have been applied on control trials), and in this case microstimulation evoked saccades (suprathreshold trials) on $43 \%$ of stimulation trials, driving a saccade of $\sim 8^{\circ}$ to the left. On suprathreshold trials, the subject looked back to the fixation point after the evoked saccade. On subthreshold trials, fixation remained stable for the remainder of the fixation period and did not exhibit any systematic drift in eye position.

All trials showed a general fluctuation in pupil diameter throughout the fixation interval (Fig. 2A). However, pupil diameter did not exhibit any systematic change on control trials. In contrast, stimulation in most trials was followed by clear pupil dilation, both on suprathreshold (red) and subthreshold (blue) trials. Pupil dilation tended to be larger on suprathreshold versus subthreshold trials, even when pupil dilation was assessed after the return saccade to the fixation point (Fig. $2 A, C$ ). This was a consistent observation across all of our data set. However, because the presence and timing of the evoked and the returning saccade may confound measurements of pupil diameter, most of our remaining analyses focus on pupil dilation during subthreshold trials without any accompanying evoked saccade.

For this representative stimulation site, the magnitude of pupil dilation on subthreshold trials scaled with stimulation current. This is shown in Figure 2D, which displays averaged pupil diameter for the five different stimulation currents applied at this site (ranging between 20 and $40 \mu \mathrm{A}$, in steps of $5 \mu \mathrm{A}$ ). When compared to pupil diameter on control trials without stimulation, clear pupil dilation was induced at all stimulation levels. Such dilation began near the end of the stimulation interval ( 150-200 ms after stimulation onset), peaked $\sim 300-400 \mathrm{~ms}$ after stimulation, and then reversed by constricting again.

\section{Pupil dilation scales with microstimulation intensity}

Consistent with our representative data, pupil dilation on subthreshold trials scaled systematically with stimulation current. This is shown in Figure 3, averaged across all stimulation sites ( 50 sites in Animal C, 31 sites in Animal S) for the different stimulation levels and control trials. We emphasize that these measurements of pupil diameter are taken from subthreshold trials without accompanying evoked saccades; hence, more trials contribute to the averages at the lowest versus highest stimulation levels. 
A

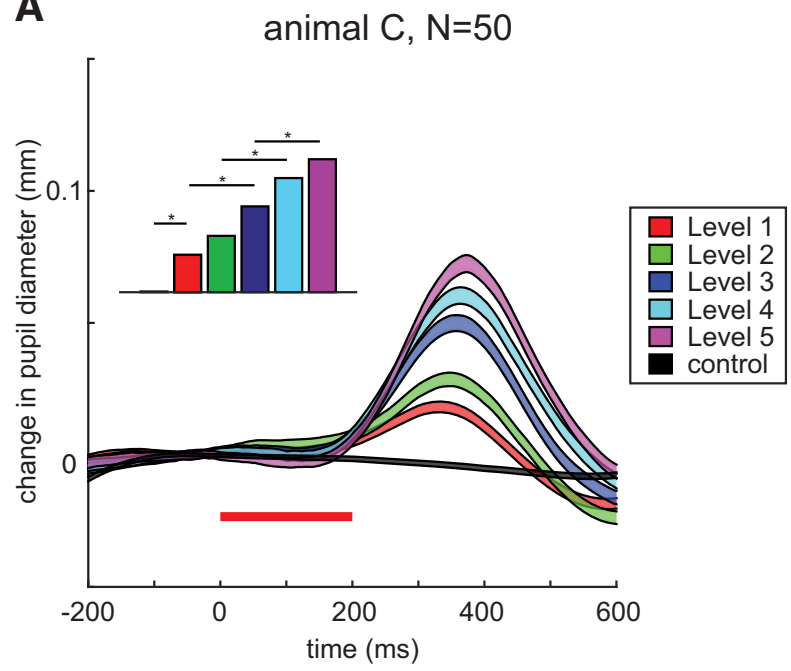

B

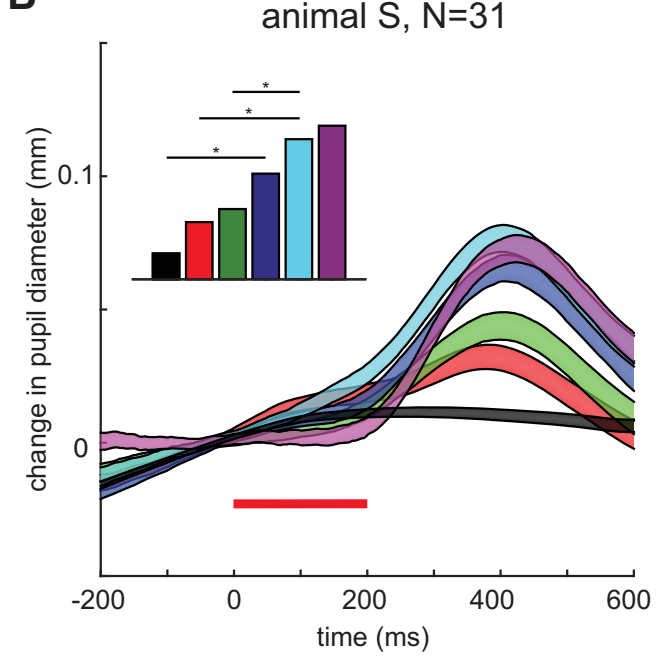

Figure 3. Subthreshold microstimulation induced pupil dilation. $A, B$, Averaged change in pupil dilation time induced by different stimulation levels compared to controls, depicted for both animals. The same format as in Figure $2 D$ is used. Insets in the top left corner indicate statistical differences between induced dilation for individual stimulation levels ( $n$-way ANOVA, corrected for multiple comparisons, ${ }^{*} p<0.05$ ).

\section{Level 1}

Level 2

Level 3

Level 4

Level 5

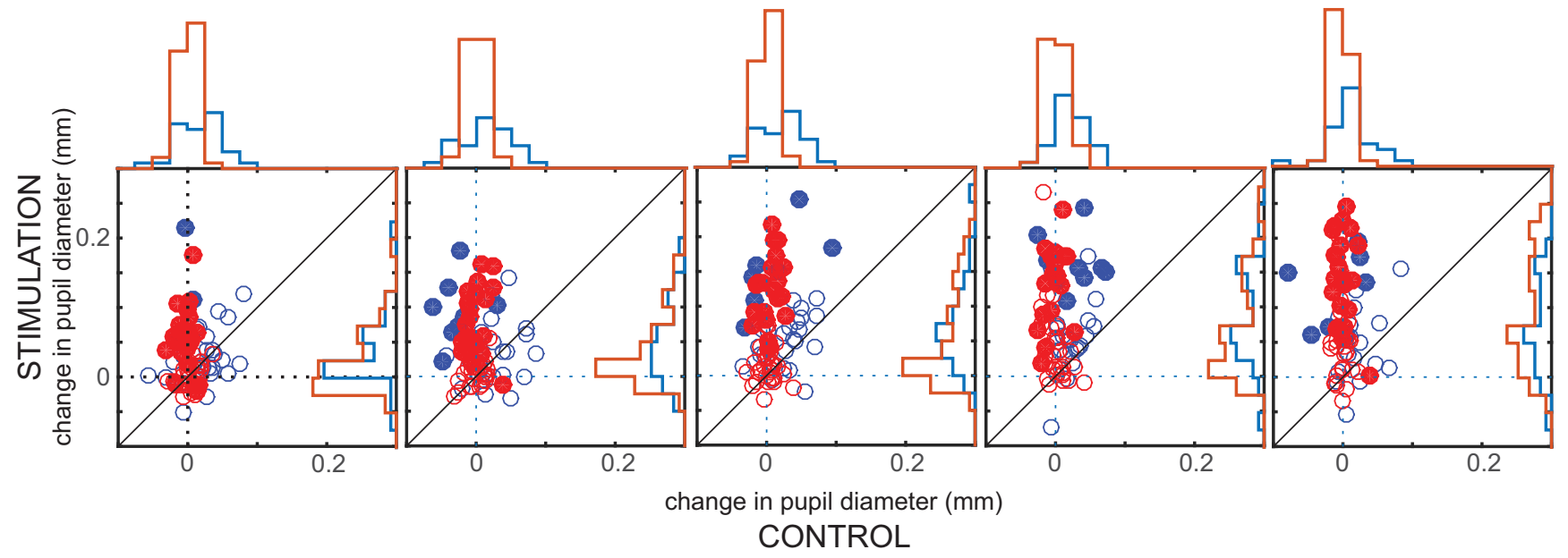

\begin{tabular}{|clc|}
\hline 0 & animal S $\quad N=81$ \\
0 & animal C $\quad N=0.05$ \\
significant (ttest $p<0$
\end{tabular}

Figure 4. Comparison of induced pupil dilation on subthreshold versus control trials. Scatter plots comparing the changes in pupil diameter after subthreshold microstimulation with the controls for each site and animal across the different stimulation levels. Each circle shows data from an individual stimulation site and is filled if there was a significant within-site difference $(t$ test, $p<0.05)$. Histograms at the top (control) and right sides (stimulation) depict the distribution of pupil changes across sites.

The insets in the top left corner show the statistical differences between induced dilation for different stimulation levels. The induced dilation was measured as the difference between the maximal pupil diameter in a certain response window (300-500 ms after stimulation onset) and a baseline window (averaged across $100 \mathrm{~ms}$ before stimulation onset) for each site and level (asterisks indicate the smallest significant step between the different levels with an $n$-way ANOVA, corrected for multiple comparisons, $p<0.05)$. For Animal C, induced pupil dilation for all stimulation levels was significantly larger than on control trials, and induced dilation generally scaled with increasing stimulation intensity. Similar graded pupil dilation that increased with stimulation current was also observed in Animal S, although the differences between stimulation levels were not as distinct as in Animal C.
To quantify the induced pupillary changes in more detail and to display the variance within our sample, we compared the pupil response on subthreshold trials to control trials separately for each site and stimulation level (Fig. 4). For all five levels, the averaged change in pupil diameter for subthreshold trials (i.e., the difference between the response and baseline window) was plotted against that measured from corresponding control trials (red for Animal C, blue for Animal S). On all levels, subthreshold simulation generally induced pupil dilation, with a substantial amount of sites showing a statistically significant within-site difference in diameter change between subthreshold and control trials (filled circles; $t$ test, $p<0.05$ ).

In addition, the distributions of these pupillary changes are presented as histograms at the top (control) and right sides (stim- 


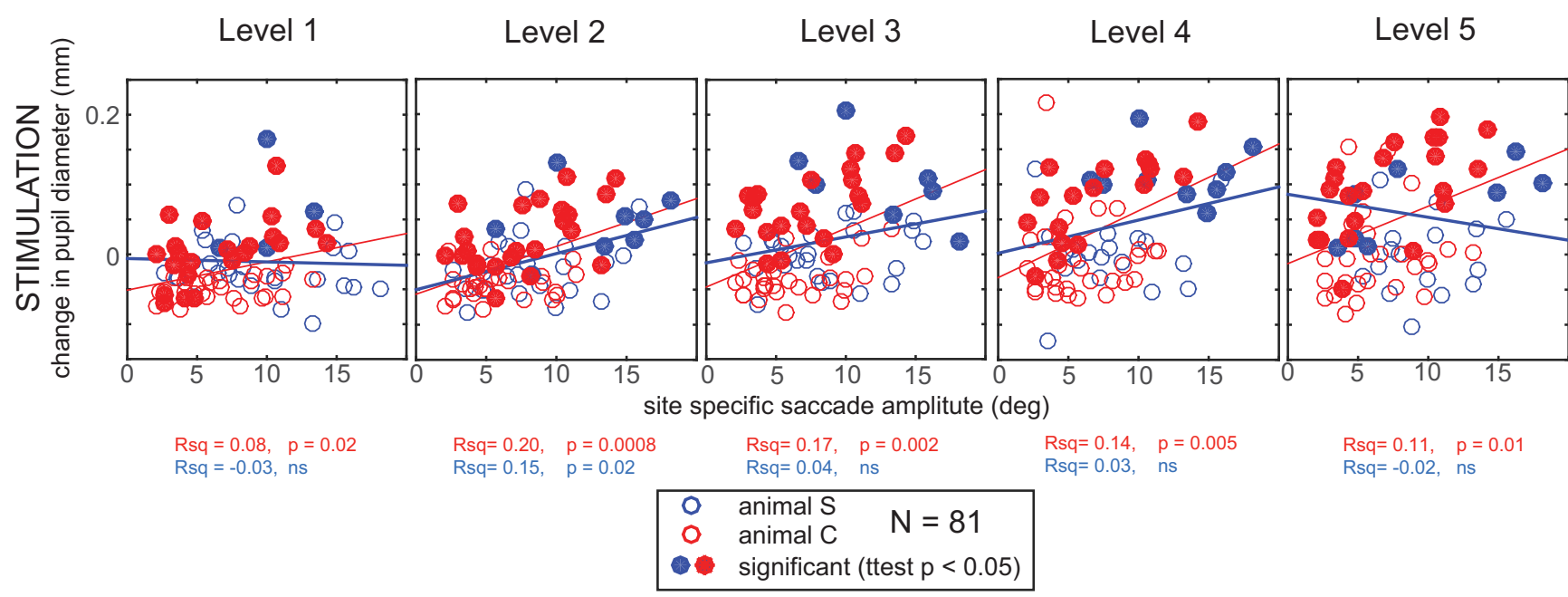

Figure 5. Relationship between induced pupil response and site-specific saccade amplitude. Scatter plots of the induced change in pupil diameter on subthreshold trials versus the site-specific saccade amplitude taken from suprathreshold trials at the highest stimulation level. Each circle shows data from an individual stimulation site and is filled if there was a significant within-site difference between dilation on subthreshold versus control trials ( $t$ test, $p<0.05$ ). Lines represent the regressions of linear fit for each subject. $R^{2}$ and $p$ values are listed underneath the plots separately for each animal.

ulation) of the panels in Figure 4. Displaying the data this way again emphasizes the larger degree of pupil dilation on subthreshold versus control trials. Moreover, notice how the variability in pupil dilation increases for higher stimulation levels on subthreshold trials (i.e., the spread of the $y$-axis histograms), but stays the same for control trials (i.e., the spread of the $x$-axis histograms).

\section{A moderate relationship between pupil dilation and site- specific saccade amplitude}

In addition, we analyzed the relationship between induced pupil dilation and the evoked site-specific saccade amplitude obtained at the highest stimulation level. Our results are shown in Figure 5, segregated by the level of stimulation current, and reveal substantial variability across subjects and across stimulation currents. Larger pupil dilation tended to accompany stimulation at sites evoking larger saccades for all stimulation levels in Animal C (red circles and regression lines, see also results of a linear correlation underneath each panel) but not Animal S (blue circles and lines). Furthermore, pupil dilation was weakly related to the horizontal component of evoked saccades in Animal C; the vertical component, as well as vectorial saccade direction, did not show a relation to pupil diameter in both monkeys (data not shown). Note as well in both subjects that significant induced pupil dilation, which is indicated by filled circles, was not restricted to any particular range of site-specific amplitudes, with many occurrences of significant within-site evoked pupil dilation occurring at sites associated with site-specific amplitudes of $<5^{\circ}$. Thus, significant dilation could be evoked in sites associated with any sized saccade.

\section{Induced pupil dilation is not a by-product of other eye motion}

Microstimulation of FEFs has been reported to induce other oculomotor responses, such as smooth pursuit eye movements (Gottlieb et al., 1994) and vergence (Gamlin and Yoon, 2000). Changes in pupil diameter are also associated with changes in vergence angle during the near-triad response; if this is driving the pupil responses, then dilation should be accompanied by divergence, or leftward motion of the left eye. Is it possible that the observed microstimulation-induced pupil dilation accompanies or is a by-product of other oculomotor phenomena? To rule out this possibility, we reanalyzed our data after removing any trial where eye position during fixation over the analyzed fixation interval changed by $0.5^{\circ}$ in either the horizontal or vertical dimension (16.1\% of trials removed for Animal C, 38.9\% of trials removed for Animal S). Our rationale was that reducing the database with this strict criterion should remove any pupil dilation, if such dilation was due to smooth pursuit or motion of the left eye related to changes in vergence angle. However, as shown in Figure 6, ICMS induced pupil dilation remained essentially unchanged compared to controls in both subjects after database reduction. Thus, prominent pupil dilation can still be evoked from the FEFs even when the eyes are essentially stable during the fixation interval, suggesting that slow eye movements associated with smooth pursuit or changes in vergence angle are not confounding this result.

\section{Variation of other stimulation factors: duration and frequency}

The frequency and duration of stimulation in the oculomotor system also influence the probability and metrics of evoked saccades (Stanford et al., 1996; Tehovnik and Sommer, 1997; Kimmel and Moore, 2007; Katnani and Gandhi, 2012). To further understand the nature of the induced pupil dilation, in a total of 16 FEF sites (Animal S, 14 sites; Animal C, 2 sites), we systematically explored the effects of stimulation frequency and duration on evoked pupil dilation. After determining the threshold current for each site, we then varied either the stimulation frequency $(50,100,150,200$, and $250 \mathrm{~Hz}$ for $200 \mathrm{~ms})$ or duration $(30,70$, 100,135 , and $165 \mathrm{~ms}$ at $300 \mathrm{~Hz}$ ) within the same site. As shown in Figure 7, pupil dilation scaled up with increases in either stimulation frequency (Fig. 7A) or duration ( $B$; as before, we only show pupil measures for subthreshold trials without any evoked saccade). These results largely resemble what we observed when varying stimulation current (Fig. 3 ).

The choice of the stimulation parameters made it possible to directly compare the effects of duration and frequency for these sites; note how a given level delivers the same number of stimulation pulses regardless of whether frequency or duration was 


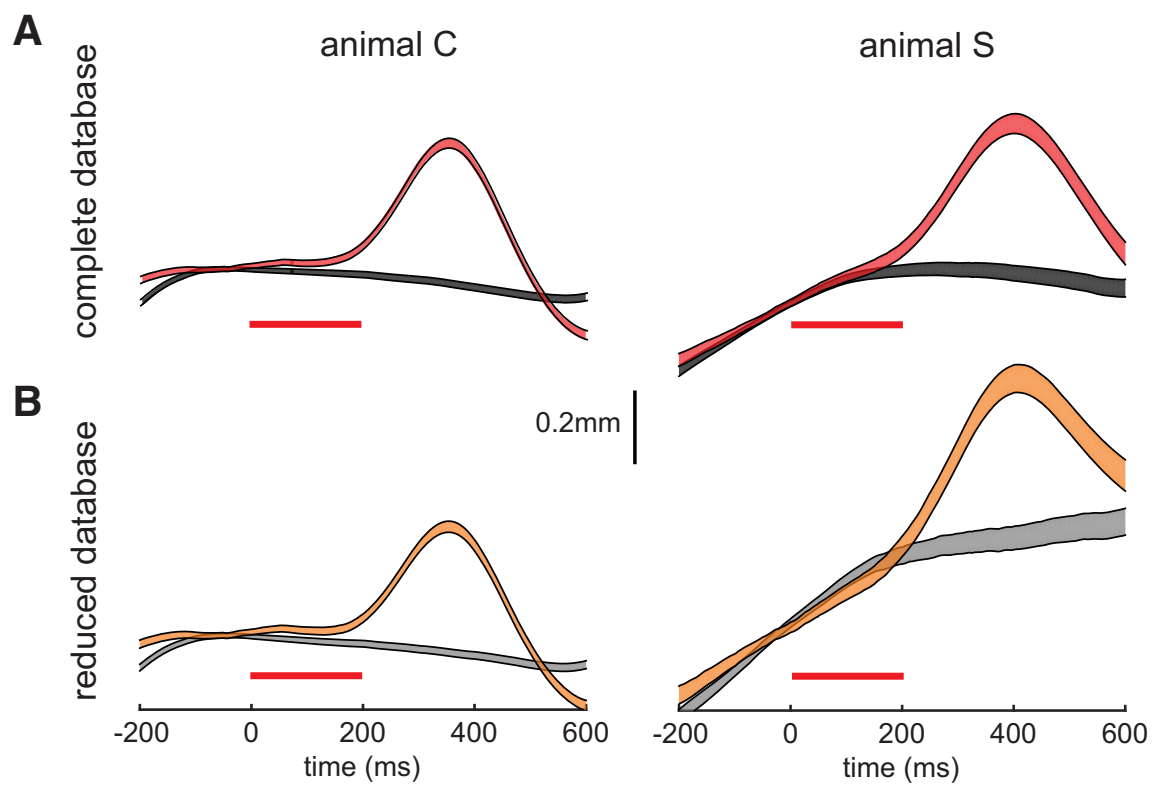

Figure 6. Induced pupil dilation is not a by-product of other slow eye movements. $A, B$, To test the potential contribution of other eye movements, we restricted our database by removing subthreshold and control trials where eye positioned changed by $>0.5^{\circ}$ during fixation. Pupil dilation on subthreshold trials was essentially unchanged either before $(\boldsymbol{A})$ or after we applied this strict criterion $(\boldsymbol{B})$. The same format as in Figure $2 D$ is used.

varied (levels 1 through 5 deliver pulses in increasing numbers of $10)$. When comparing the induced pupil dilation for all 16 sites across the five levels, we found the magnitude of induced pupil dilation to be highly correlated regardless of whether frequency or duration was varied (Fig. $7 C$; correlation coefficient, 0.71 ; linear fit, $\left.R^{2}=0.5, p=2.6 * 10^{-13}\right)$. When displaying the same data as a function of the number of pulses, we found highly similar and overlapping response curves regardless of whether stimulation frequency or duration was varied (Fig. 7D).

\section{Relationships between induced pupil dilation and endogenous activity at the time of stimulation}

The pupil dilation induced by FEF microstimulation is similar to what follows stimulation in the monkey SCi or the optic tectum in owls (Wang et al., 2012, Netser et al., 2010). To further explore the potential substrate underlying induced pupil dilation, we checked for functional relationships between pupil dilation and other aspects of oculomotor behavior. One way of doing this is to explore pupil responses on suprathreshold trials with evoked saccades, after subdividing such trials into those where stimulation induced saccades in an early (e.g., 50-100 ms after stimulation onset) or late (100-150 ms) interval. Our assumption here is that the earlier saccades are associated with a higher level of endogenous excitation within the oculomotor system at stimulation onset; many previous studies have used a similar logic to infer activation within the oculomotor system based on the properties of evoked saccades (Barborica and Ferrera, 2004; Juan et al., 2004) or other nonsaccadic components of orienting (Moore and Fallah, 2001; Corneil et al., 2007; Chapman and Corneil, 2014). As predicted, pupil dilation assessed after the return saccade back to the fixation point was systematically greater when accompanied by "early" versus "late" evoked saccades (Fig. 8). This result is consistent with a role for the oculomotor system in pupil dilation evoked from the FEF.

\section{Prominent evoked pupil dilation outside of the FEF}

We also observed many instances where we observed prominent pupil dilation evoked by stimulation delivered outside of the canonical FEF, where our standard stimulation trains $(50 \mu \mathrm{A}, 200 \mathrm{~ms}, 300$ $\mathrm{Hz}$ ) failed to evoke any saccade. Such observations were common enough in both animals to warrant a brief description, although our setup precluded precise quantification of comparative response thresholds for sites not evoking saccades. In some instances, further lowering positioned the electrode within the FEF; hence, pupil dilation in such cases may have simply arisen from the spread of stimulation into the nearby FEF. However, we also observed pupil dilation following stimulation at sites either rostral and caudal to the FEF, in areas where further lowering of the electrode never caused it to enter the FEF. All aspects of the pupil response in such instances resembled that evoked from the FEF. Stimulation at sites rostral to the FEF evoked no overt responses other than pupil dilation. Stimulation at caudal sites provoking pupil dilation with currents of $50 \mu \mathrm{A}$ or less could also evoke muscle twitches of the arm and shoulder; hence, we attributed such sites to the posterior bank of the arcuate sulcus or the premotor cortex. These observations suggest that pupil dilation may be a common consequence of microstimulation to the periarcuate cortex.

\section{Effects of FEF microstimulation on subsequent visually guided saccades}

As mentioned in the Materials and Methods, our task explicitly imposed a large separation between the time of FEF microstimulation and the initiation of a visually guided saccade; this was done so that any effects of FEF microstimulation on pupil diameter would presumably not be confounded by other task-related influences. Nevertheless, analysis of the visually guided saccades may help shed further light on the behavioral effects of microstimulation. For example, is it possible that FEF microstimulation influences subsequent behavior, perhaps by arousing the animal? We conducted two analyses to examine this possibility.

First, we analyzed the saccadic reaction time (RT) on subthreshold stimulation trials. Although stimulation preceded the voluntary saccade by $\sim 1 \mathrm{~s}$, we found a very small and lateralized effect of FEF microstimulation. Compared to no-stimulation trials, FEF stimulation increased leftward (contralateral to the side of stimulation) RTs by $5 \mathrm{~ms}$ for Animal S (control, $143 \pm 24 \mathrm{~ms}$, mean $\pm \mathrm{SD} ; n=2606$; stimulation, $148 \pm 23 \mathrm{~ms}, n=1399$; Wilcoxon rank sum test, $p<1.8 * 10^{-4}$ ) and $3 \mathrm{~ms}$ for Animal C (control, $125 \pm 23 \mathrm{~ms}, n=2349$; stimulation, $128 \pm 28 \mathrm{~ms}, n=$ $1340 ; p<1.8 * 10^{-9}$ ). In comparison, FEF stimulation did not influence the RT of rightward (ipsilateral) saccades in Animal S (control, $159 \pm 18 \mathrm{~ms}$, mean $\pm \mathrm{SD} ; n=2612$; stimulation, $159 \pm$ $18 \mathrm{~ms}, n=1401$; Wilcoxon rank sum test, n.s.) or Animal C (control, $134 \pm 24 \mathrm{~ms}, n=2366$; stimulation, $135 \pm 27 \mathrm{~ms}, n=$ 1368 ; n.s.). Although very small, the lateralized effect of FEF mi- 
A

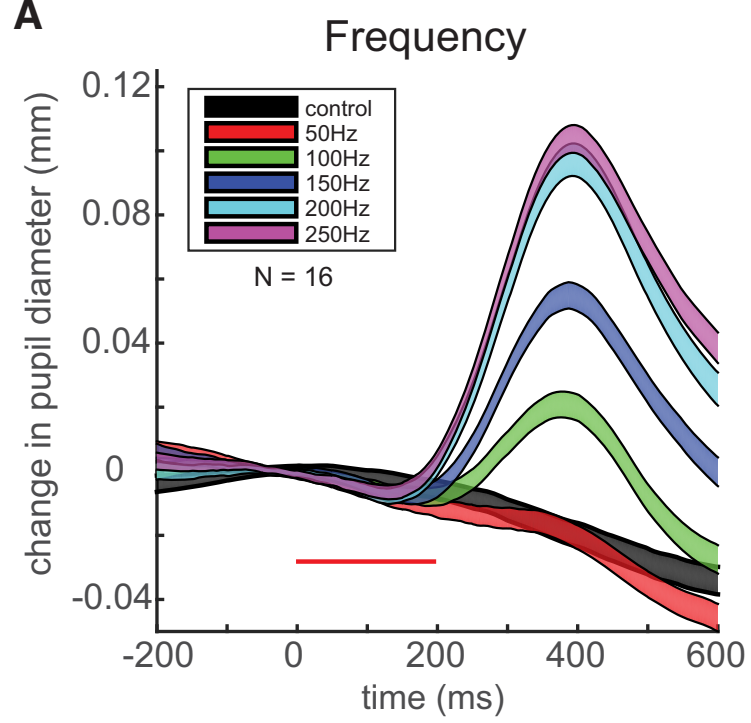

C

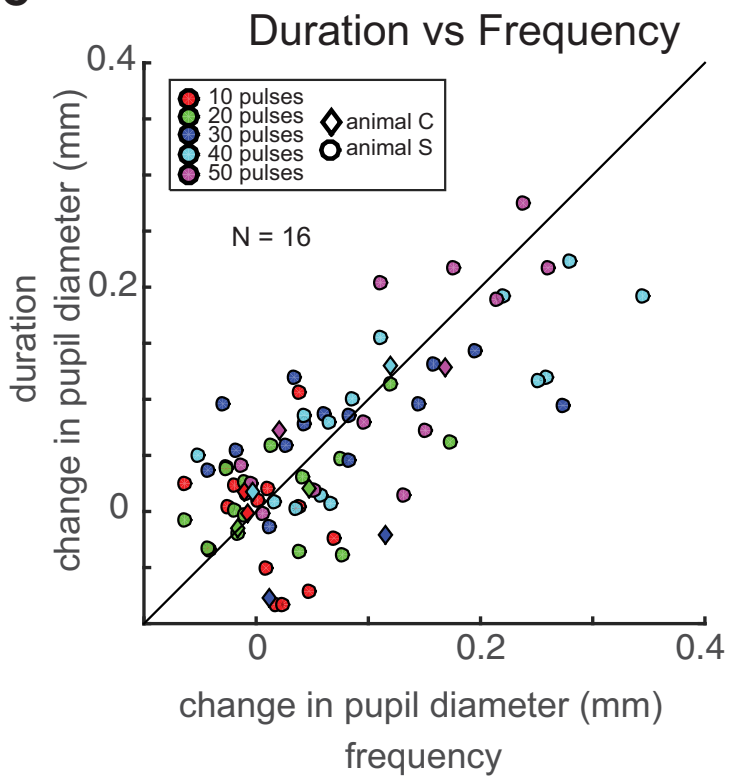

B

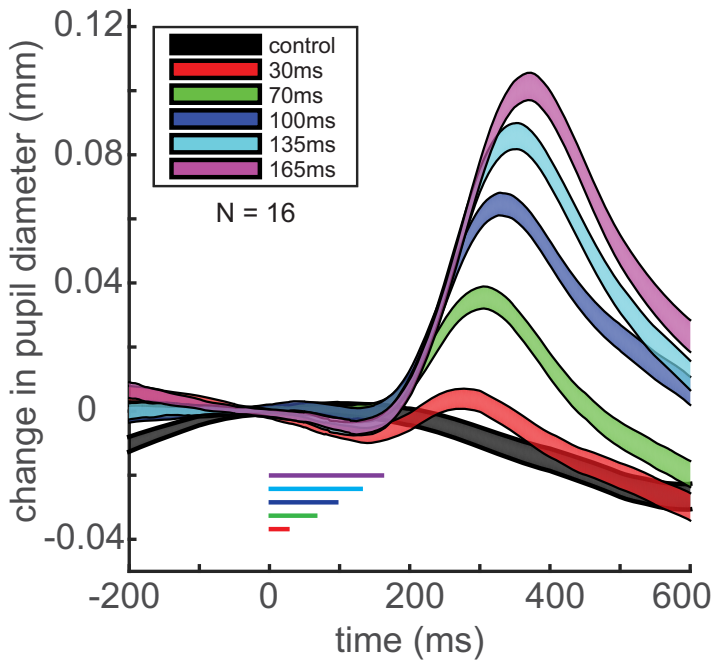

D

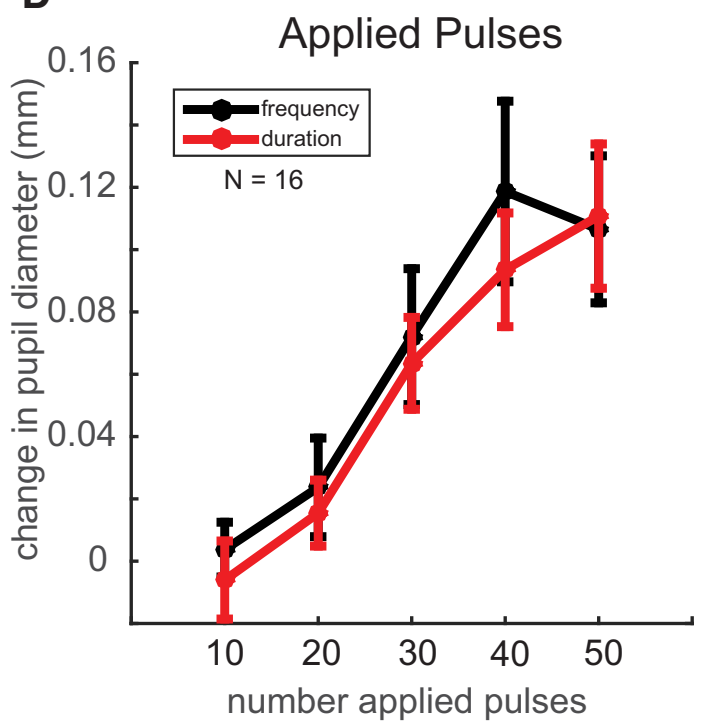

Figure 7. Variation of stimulation frequency or duration. $\boldsymbol{A}, \boldsymbol{B}$, Change in pupil diameter after varying stimulation frequency $(\boldsymbol{A})$ or duration $(\boldsymbol{B})$ across 16 sites. The same format as in Figure $2 D$ is used. C, Comparison of induced pupil dilation on subthreshold trials when varying either duration or frequency. Each symbol shows data taken from the same stimulation where the same number of pulses was applied (colors show the different number of pulses). The diagonal line shows the line of unity. $\boldsymbol{D}$, Induced pupil dilation as a function of the number of applied pulses, taken from variations in frequency (black) or duration (red). Error bars indicate the SE.

crostimulation on subsequent contralateral but not ipsilateral saccades argues against a simple arousal effect.

Second, if FEF microstimulation was somehow arousing the animal, one could expect greater effects with higher levels of FEF microstimulation; after all, FEF stimulation at level 5 evoked saccades on $\sim 80 \%$ of stimulation trials. Against this possibility, an analysis of RT on control trials without stimulation revealed no effect of the level of microstimulation current on saccadic RT (Kruskal-Wallis test for five samples; n.s. in both animals for either leftward or rightward saccades). Thus, FEF stimulation did not influence saccadic behavior on nonstimulation trials.

\section{Discussion}

Low levels of FEF microstimulation, below that required to evoke saccades, evokes robust pupil dilation. Our results add to the list of nonsaccadic effects that can be driven by FEF microstimula- tion. The magnitude of pupil dilation scales with stimulation parameters, with stimulation current and the number of pulses being the key determinants. Furthermore, the relationship with early and late evoked saccades suggests that evoked pupil dilation is also a function of endogenous oculomotor activity at stimulation onset. Together, these results suggest that the oculomotor system can provide a substrate by which cognitive processes can influence pupil dilation.

\section{Comparisons to microstimulation of $\mathrm{SCi}$}

Our results are largely similar to reports of induced pupil dilation following subsaccadic microstimulation of the monkey SCi (Wang et al., 2012), where dilation began $\sim 150 \mathrm{~ms}$ after stimulation onset. Pupil dilation induced from the FEF started around the same time. The slow response dynamics of the pupil complicate comparison of response latencies from the two structures, 


\section{supra-threshold}
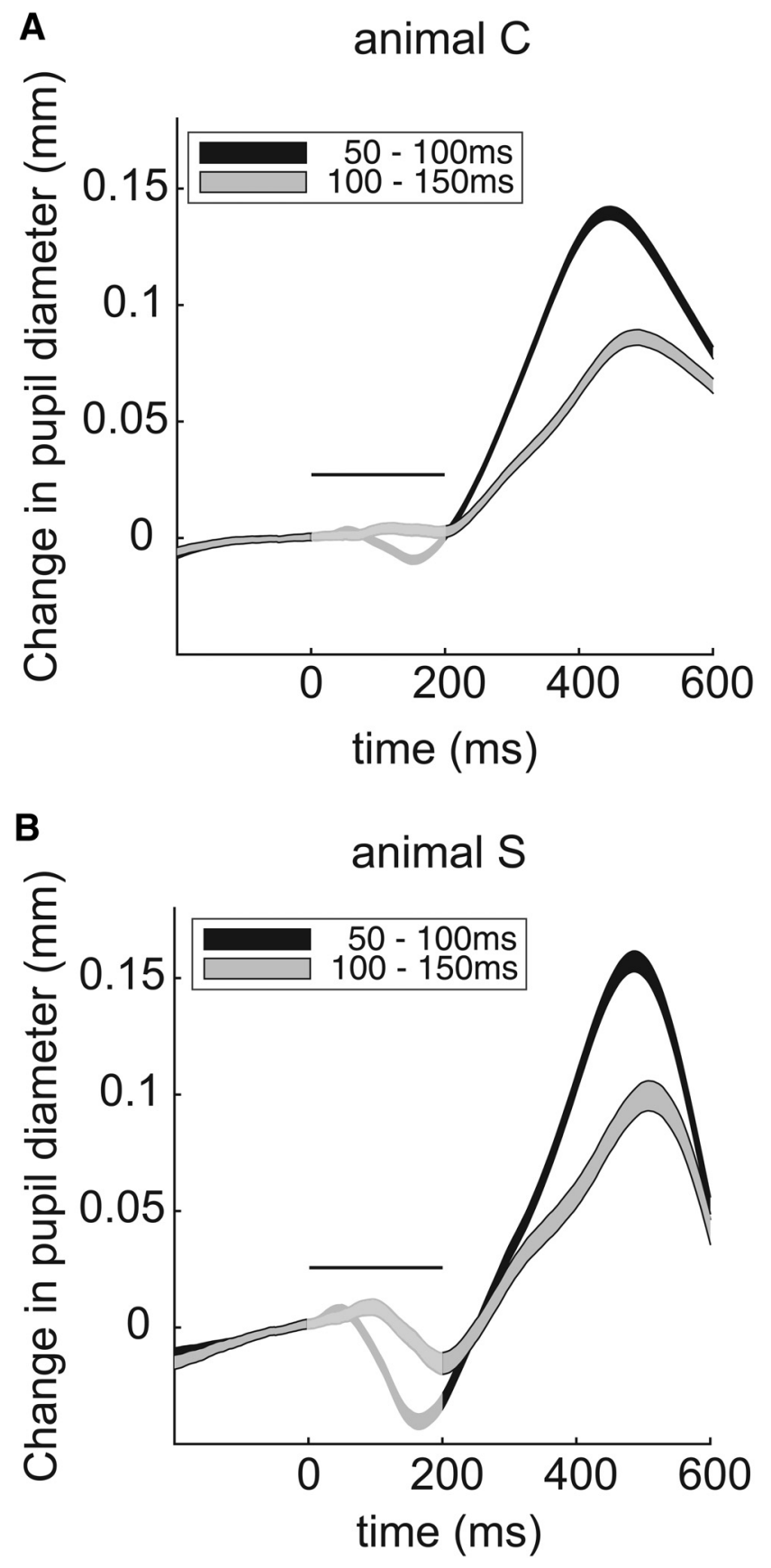

Figure 8. Pupil dilation varies with presumed endogenous oculomotor activity at the time of stimulation. $\boldsymbol{A}, \boldsymbol{B}$, Induced pupil dilation on suprathreshold trials, segregated by the comparatively short (black) or long (gray) latency of the evoked saccade. The same general format as in Figure $2 D$ is used, with traces made more faint during the time of stimulation since evoked eye movements can distort measurements of pupil diameter.

particularly since the propagation time between the FEF and SCi is $<5 \mathrm{~ms}$ (Segraves and Goldberg, 1987; Sommer and Wurtz, 1998). In addition, although we reported considerably larger pupil dilation (averaging $\sim 0.1 \mathrm{~mm}$ at level 5 compared to $0.05 \mathrm{~mm}$ in SCi), this strongly scaled with the current intensity (Figs. 3, 4) and number of pulses (Fig. 7). The current used by Wang et al. (2012) was " $50-70 \%$ of saccade threshold," which is similar to our level 2 currents, which evoked dilation of $\sim 0.05 \mathrm{~mm}$ (Fig. 4; although we typically stimulated for 200 rather than $100 \mathrm{~ms}$ ). Thus, our results are very similar to that evoked from the $\mathrm{SCi}$, despite differences in task and background illumination.

In contrast to what was reported in the $\mathrm{SCi}$, in one animal we found a modest relationship for larger pupil dilation accompanying stimulation at FEF sites associated with larger saccades (Fig. 5). This relationship was not observed in the other animal, and in both animals we observed occurrences where significant pupil dilation could be evoked from stimulation sites associated with saccades $<5^{\circ}$. These observations argue against pupil dilation arising secondary to processes that scale with larger evoked saccades, such as neck muscle recruitment (Elsley et al., 2007). Furthermore, FEF saccadic thresholds are lower than neck muscle thresholds for sites evoking saccades $<6-7^{\circ}$ (Corneil et al., 2010), meaning that the subthreshold currents capable of inducing pupil dilation from small-saccade sites would not have recruited neck muscles.

\section{Could evoked pupil dilation be secondary to other percepts?}

Although we can rule out neck muscle recruitment as a proximate cause of pupil dilation, could the pupil be dilating due to other induced percepts? In patients, frontal stimulation can invoke a feeling of movement as well as an urge to move, even without movement (Fried et al., 1991). Monkeys can reliably detect in which of two intervals subthreshold stimulation is passed in the FEFs (Murphey and Maunsell, 2008) and elsewhere (Murphey and Maunsell, 2007), and FEF microstimulation can provoke widespread changes in the activity of many brain areas (Moore and Armstrong, 2003; Ekstrom et al., 2008; Premereur et al., 2012). Questions about percepts arising from cortical stimulation are vexing in animal models, particularly given uncertainty regarding the form and timing of any associated percept. In their work, Murphey and Maunsell (2008) suggested that FEF microstimulation may be inducing a phosphene similar to that evoked in visual cortices, or evoking some other form of arousal. One interpretation of our results is that pupil dilation may be a consequence of such a percept or arousal; alternatively, pupil dilation may itself lead to a percept of increased brightness, which the animal then reports.

Against these possibilities, it is important to remember that the latencies of evoked pupil dilation from the FEFs were $<200$ ms. Pupil responses to FEF stimulation are considerably slower than the latencies of evoked neck muscle responses ( $\sim 20-30 \mathrm{~ms}$; Elsley et al., 2007; Corneil et al., 2010), saccades (20-60 ms; Bruce et al., 1985), changes in V4 activity (20-40 ms; Armstrong and Moore, 2007), or increased contrast sensitivity (50-175 ms; Moore and Fallah, 2004). Therefore, these induced effects are too fast to be explained by stimulation-induced pupil dilation. Similarly, FEF microstimulation modulates contrast response functions measured via neuroimaging in extrastriate areas (Ekstrom et al., 2009), but the preferential modulation for low-contrast stimuli is consistent with deployment of visuospatial attention rather than pupil dilation.

Despite the comparatively long latencies for evoked pupil versus other responses, the pupil response latencies from the FEF approach the minimal feedforward response latency through the downstream pupil circuitry. In the monkey, changes in pupil diameter occur within $\sim 300$ or $\sim 450 \mathrm{~ms}$ of an increase or decrease in overall luminance, respectively, and within $\sim 220$ to 260 $\mathrm{ms}$ (visual) or $\sim 160$ to $220 \mathrm{~ms}$ (auditory) after onset of salient stimuli known to induce SCi activity (Wang et al., 2014). Thus, although we cannot definitely rule out the possibility that evoked 
pupil dilation is secondary to other percepts, this seems unlikely given the sluggish response dynamics of the pupil.

\section{Which circuits could be mediating the induced pupil response?}

Pupil measures have often been used as noninvasive proxies of arousal, based in part on close relationships between LC activity and pupil diameter (Gilzenrat et al., 2010; Joshi et al., 2016). Previous work shows that orienting circuits in the midbrain can also drive pupil dilation (Wang and Munoz, 2015). As mentioned above, many aspects of our results are consistent with FEF stimulation driving pupil responses through the SCi. However, we are mindful that the FEF is also interconnected with arousal circuits, potentially via the ACC, which itself is strongly interconnected with both the PGi and LC (Wang et al., 2004; Vogt et al., 2008; Nieuwenhuis et al., 2011; Procyk et al., 2016). The SC also receives noradrenergic input from the LC (Edwards et al., 1979; Morrison and Foote, 1986), further complicating matters. Our task was not designed to disentangle the contribution of orienting versus arousal circuits, and although influence of FEF stimulation on the RT of subsequent contralateral but not ipsilateral saccades seems inconsistent with arousal, such effects were very small. Definitive evidence that pupil dilation evoked by FEF stimulation is mediated via the SCi rather than the PGi or LC may require approaches similar to that adopted by Hanes and Wurtz (2001), who examined changes in saccades evoked from the FEFs following inactivation of the SCi.

Regardless, the tight anatomical intertwining of arousal and orienting circuits that access autonomic pupil circuits may facilitate behavior in a variety of contextual scenarios. For example, nonspatial cues for anticipated effort in monkeys provide topdown input to arousal circuits, increasing LC activity and pupil dilation (Varazzani et al., 2015); such increases in noradrenergic tone are thought to help mobilize the autonomic and physiological resources, including the orienting system, needed to meet an anticipated challenge (Sara and Bouret, 2012). As another example, top-down input prioritizing particular spatial locations, presumably encoded by the orienting system via covert visuospatial attention, could engage the arousal system about a potentially important upcoming event. Accordingly, the arousal and orienting circuits, and the ways in which top-down contextual input could engage them to drive pupil dilation, need not be mutually exclusive.

Stimulation outside the FEF also induced prominent pupil dilation. Stimulation caudal to the functionally defined FEF paired pupil dilation with clear skeletomotor responses, implicating the premotor cortex and posterior bank of the arcuate sulcus. Stimulation at sites rostral to the FEF evoked pupil dilation without any other obvious overt motor responses, and presumably corresponded to the prearcuate area 8 . These observations are still consistent with circuits through the FEF, PGi, LC, and SCi: both prearcuate areas and dorsal premotor cortex are interconnected with the FEF, and both areas project to the intermediate and deep layers of the SC (Huerta et al., 1987; Stanton et al., 1993; Distler and Hoffmann, 2015). Moreover, the functional definition of the FEF as the area from which saccades can be evoked with currents $<50 \mu \mathrm{A}$ may be overly conservative. Anatomical and functional work shows that the periarcuate eye fields are quite extensive and encompass premotor area 6 and much of the prearcuate convexity (Fujii et al., 1998, 2000; Moschovakis et al., 2004; Savaki et al., 2014). Furthermore, pupil dilation may be a component of the repertoire of nonsaccadic movements that can be provoked by stimulation of these regions outside of the classic saccade-related FEF, including smooth pursuit (Gottlieb et al., 1994), vergence (Gamlin and Yoon, 2000), or eye movements accompanying defensive movements (Boulanger et al., 2009). Ultimately, pupil dilation may be a common product of frontal cortex microstimulation; hence, future studies should measure the pupil, particularly in tasks incorporating a perceptual or behavioral component.

\section{Conclusion}

Our results demonstrate that FEF stimulation can provoke prominent pupil dilation without saccades. Such findings reinforce the notion that pupil measures may provide a quantifiable, and more permissive, reflection of subthreshold oculomotor activity, consistent with differences in the premotor circuits governing saccadic versus nonsaccadic responses in the brainstem (for review, see Corneil and Munoz, 2014). More broadly, the oculomotor system may provide a substrate by which cognitive processes influence pupil diameter, working in conjunction with arousal circuits. Given the myriad cognitive processes that can influence pupil diameter, it may be possible that future research can ascribe some processes to the oculomotor system and others to arousal circuits. Task-dependent modulation of pupil diameter via the oculomotor system may be particularly important during the deployment of visuospatial attention, facilitating the detection of expected but low-contrast visual stimuli by coordinating pupil dilation with attentional modulation of activity within early visual cortex.

\section{References}

Ahern S, Beatty J (1979) Pupillary responses during information processing vary with Scholastic Aptitude Test scores. Science 205:1289-1292. CrossRef Medline

Armstrong KM, Moore T (2007) Rapid enhancement of visual cortical response discriminability by microstimulation of the frontal eye field. Proc Natl Acad Sci U S A 104:9499-9504. CrossRef Medline

Arnsten AF, Goldman-Rakic PS (1984) Selective prefrontal cortical projections to the region of the locus coeruleus and raphe nuclei in the rhesus monkey. Brain Res 306:9-18. CrossRef Medline

Aston-Jones G, Cohen JD (2005) An integrative theory of locus coeruleusnorepinephrine function: adaptive gain and optimal performance. Annu Rev Neurosci 28:403-450. CrossRef Medline

Barborica A, Ferrera VP (2004) Modification of saccades evoked by stimulation of frontal eye field during invisible target tracking. J Neurosci 24: 3260-3267. CrossRef Medline

Boulanger M, Bergeron A, Guitton D (2009) Ipsilateral head and centring eye movements evoked from monkey premotor cortex. Neuroreport 20 : 669-673. CrossRef Medline

Bruce CJ, Goldberg ME, Bushnell MC, Stanton GB (1985) Primate frontal eye fields. II. Physiological and anatomical correlates of electrically evoked eye movements. J Neurophysiol 54:714-734. Medline

Chapman BB, Corneil BD (2014) Short-duration stimulation of the supplementary eye fields perturbs anti-saccade performance while potentiating contralateral head orienting. Eur J Neurosci 39:295-307. CrossRef Medline

Corneil BD, Munoz DP (2014) Overt responses during covert orienting. Neuron 82:1230-1243. CrossRef Medline

Corneil BD, Munoz DP, Olivier E (2007) Priming of head premotor circuits during oculomotor preparation. J Neurophysiol 97:701-714. CrossRef Medline

Corneil BD, Elsley JK, Nagy B, Cushing SL (2010) Motor output evoked by subsaccadic stimulation of primate frontal eye fields. Proc Natl Acad Sci U S A 107:6070-6075. CrossRef Medline

Costello MG, Zhu D, Salinas E, Stanford TR (2013) Perceptual modulation of motor-but not visual-responses in the frontal eye field during an urgent-decision task. J Neurosci 33:16394-16408. CrossRef Medline

Dean P, Redgrave P, Westby GW (1989) Event or emergency? Two response systems in the mammalian superior colliculus. Trends Neurosci 12: 137-147. CrossRef Medline 
de Gee JW, Knapen T, Donner TH (2014) Decision-related pupil dilation reflects upcoming choice and individual bias. Proc Natl Acad Sci U S A 111:E618-E625. CrossRef Medline

Distler C, Hoffmann KP (2015) Direct projections from the dorsal premotor cortex to the superior colliculus in the macaque (Macaca mulatta). J Comp Neurol 523:2390-2408. CrossRef Medline

Edwards SB, Ginsburgh CL, Henkel CK, Stein BE (1979) Sources of subcortical projections to the superior colliculus in the cat. J Comp Neurol 184:309-329. CrossRef Medline

Einhäuser W, Stout J, Koch C, Carter O (2008) Pupil dilation reflects perceptual selection and predicts subsequent stability in perceptual rivalry. Proc Natl Acad Sci U S A 105:1704-1709. CrossRef Medline

Einhäuser W, Koch C, Carter OL (2010) Pupil dilation betrays the timing of decisions. Front Hum Neurosci 4:18. Medline

Ekstrom LB, Roelfsema PR, Arsenault JT, Bonmassar G, Vanduffel W (2008) Bottom-up dependent gating of frontal signals in early visual cortex. Science 321:414-417. CrossRef Medline

Ekstrom LB, Roelfsema PR, Arsenault JT, Kolster H, Vanduffel W (2009) Modulation of the contrast response function by electrical microstimulation of the macaque frontal eye field. J Neurosci 29:10683-10694. CrossRef Medline

Eldar E, Cohen JD, Niv Y (2013) The effects of neural gain on attention and learning. Nat Neurosci 16:1146-1153. CrossRef Medline

Elsley JK, Nagy B, Cushing SL, Corneil BD (2007) Widespread presaccadic recruitment of neck muscles by stimulation of the primate frontal eye fields. J Neurophysiol 98:1333-1354. CrossRef Medline

Everling S, Munoz DP (2000) Neuronal correlates for preparatory set associated with pro-saccades and anti-saccades in the primate frontal eye field. J Neurosci 20:387-400. Medline

Fried I, Katz A, McCarthy G, Sass KJ, Williamson P, Spencer SS, Spencer DD (1991) Functional organization of human supplementary motor cortex studied by electrical stimulation. J Neurosci 11:3656-3666. Medline

Fujii N, Mushiake H, Tanji J (1998) An oculomotor representation area within the ventral premotor cortex. Proc Natl Acad Sci U S A 95:1203412037. CrossRef Medline

Fujii N, Mushiake H, Tanji J (2000) Rostrocaudal distinction of the dorsal premotor area based on oculomotor involvement. J Neurophysiol 83: 1764-1769. Medline

Gamlin PD, Yoon K (2000) An area for vergence eye movement in primate frontal cortex. Nature 407:1003-1007. CrossRef Medline

Gilzenrat MS, Nieuwenhuis S, Jepma M, Cohen JD (2010) Pupil diameter tracks changes in control state predicted by the adaptive gain theory of locus coeruleus function. Cogn Affect Behav Neurosci 10: 252-269. CrossRef Medline

Gold JI, Shadlen MN (2000) Representation of a perceptual decision in developing oculomotor commands. Nature 404:390-394. CrossRef Medline

Gottlieb JP, MacAvoy MG, Bruce CJ (1994) Neural responses related to smooth-pursuit eye movements and their correspondence with electrically elicited smooth eye movements in the primate frontal eye field. J Neurophysiol 72:1634-1653. Medline

Gregoriou GG, Rossi AF, Ungerleider LG, Desimone R (2014) Lesions of prefrontal cortex reduce attentional modulation of neuronal responses and synchrony in V4. Nat Neurosci 17:1003-1011. CrossRef Medline

Hanes DP, Wurtz RH (2001) Interaction of the frontal eye field and superior colliculus for saccade generation. J Neurophysiol 85:804-815. Medline

Hartmann M, Fischer MH (2014) Pupillometry: the eyes shed fresh light on the mind. Curr Biol 24:R281-R282. CrossRef Medline

Huerta MF, Harting JK (1984) Connectional organization of the superior colliculus. Trends Neurosci 7:286-289. CrossRef

Huerta MF, Krubitzer LA, Kaas JH (1987) Frontal eye field as defined by intracortical microstimulation in squirrel monkeys, owl monkeys, and macaque monkeys. II. Cortical connections. J Comp Neurol 265:332-361. CrossRef Medline

Joshi S, Li Y, Kalwani RM, Gold JI (2016) Relationships between pupil diameter and neuronal activity in the locus coeruleus, colliculi, and cingulate cortex. Neuron 89:221-234. CrossRef Medline

Juan CH, Shorter-Jacobi SM, Schall JD (2004) Dissociation of spatial attention and saccade preparation. Proc Natl Acad Sci U S A 101:15541-15544. CrossRef Medline

Katnani HA, Gandhi NJ (2012) The relative impact of microstimulation parameters on movement generation. J Neurophysiol 108:528-538. CrossRef Medline
Kimmel DL, Moore T (2007) Temporal patterning of saccadic eye movement signals. J Neurosci 27:7619-7630. CrossRef Medline

Korte SM, Jaarsma D, Luiten PG, Bohus B (1992) Mesencephalic cuneiform nucleus and its ascending and descending projections serve stress-related cardiovascular responses in the rat. J Auton Nerv Syst 41:157-176. CrossRef Medline

May PJ (2006) The mammalian superior colliculus: laminar structure and connections. Prog Brain Res 151:321-378. CrossRef Medline

May PJ, Warren S, Bohlen MO, Barnerssoi M, Horn AK (2015) A central mesencephalic reticular formation projection to the Edinger-Westphal nuclei. Brain Struct Funct. Advance online publication. CrossRef Medline

McDougal DH, Gamlin PD (2015) Autonomic control of the eye. Compr Physiol 5:439-473. Medline

Moore T, Armstrong KM (2003) Selective gating of visual signals by microstimulation of frontal cortex. Nature 421:370-373. CrossRef Medline

Moore T, Fallah M (2001) Control of eye movements and spatial attention. Proc Natl Acad Sci U S A 98:1273-1276. CrossRef Medline

Moore T, Fallah M (2004) Microstimulation of the frontal eye field and its effects on covert spatial attention. J Neurophysiol 91:152-162. Medline

Morrison JH, Foote SL (1986) Noradrenergic and serotoninergic innervation of cortical, thalamic, and tectal visual structures in old and new world monkeys. J Comp Neurol 243:117-138. CrossRef Medline

Moschovakis AK, Gregoriou GG, Ugolini G, Doldan M, Graf W, Guldin W, Hadjidimitrakis K, Savaki HE (2004) Oculomotor areas of the primate frontal lobes: a transneuronal transfer of rabies virus and [14C]-2deoxyglucose functional imaging study. J Neurosci 24:5726-5740. CrossRef Medline

Murphey DK, Maunsell JH (2007) Behavioral detection of electrical microstimulation in different cortical visual areas. Curr Biol 17:862-867. CrossRef Medline

Murphey DK, Maunsell JH (2008) Electrical microstimulation thresholds for behavioral detection and saccades in monkey frontal eye fields. Proc Natl Acad Sci U S A 105:7315-7320. CrossRef Medline

Naber M, Alvarez GA, Nakayama K (2013) Tracking the allocation of attention using human pupillary oscillations. Front Psychol 4:919. Medline

Netser S, Ohayon S, Gutfreund Y (2010) Multiple manifestations of microstimulation in the optic tectum: eye movements, pupil dilations, and sensory priming. J Neurophysiol 104:108-118. CrossRef Medline

Nieuwenhuis S, De Geus EJ, Aston-Jones G (2011) The anatomical and functional relationship between the $\mathrm{P} 3$ and autonomic components of the orienting response. Psychophysiology 48:162-175. CrossRef Medline

Opris I, Barborica A, Ferrera VP (2001) On the gap effect for saccades evoked by electrical microstimulation of frontal eye fields in monkeys. Exp brain Res 138:1-7. CrossRef Medline

Papesh MH, Goldinger SD, Hout MC (2012) Memory strength and specificity revealed by pupillometry. Int J Psychophysiol 83:56-64. CrossRef Medline

Premereur E, Vanduffel W, Roelfsema PR, Janssen P (2012) Frontal eye field microstimulation induces task-dependent gamma oscillations in the lateral intraparietal area. J Neurophysiol 108:1392-1402. CrossRef Medline

Privitera CM, Renninger LW, Carney T, Klein S, Aguilar M (2010) Pupil dilation during visual target detection. J Vis 10:1-14. CrossRef Medline

Procyk E, Wilson CR, Stoll FM, Faraut MC, Petrides M, Amiez C (2016) Midcingulate motor map and feedback detection: converging data from humans and monkeys. Cereb Cortex 26:467-476. Medline

Sara SJ, Bouret S (2012) Orienting and reorienting: the locus coeruleus mediates cognition through arousal. Neuron 76:130-141. CrossRef Medline

Sara SJ, Hervé-Minvielle A (1995) Inhibitory influence of frontal cortex on locus coeruleus neurons. Proc Natl Acad Sci U S A 92:6032-6036. CrossRef Medline

Savaki HE, Gregoriou GG, Bakola S, Moschovakis AK (2015) Topography of visuomotor parameters in the frontal and premotor eye fields. Cereb Cortex 25:3095-3106. Medline

Schall JD (2015) Visuomotor functions in the frontal lobe. Annu Rev Vis Sci 1:469-498. CrossRef

Schall JD, Bichot NP (1998) Neural correlates of visual and motor decision processes. Curr Opin Neurobiol 8:211-217. CrossRef Medline

Segraves MA, Goldberg ME (1987) Functional properties of corticotectal neurons in the monkey's frontal eye field. J Neurophysiol 58:1387-1419. Medline

Sokolov EN (1963) Higher nervous functions: the orienting reflex. Annu Rev Physiol 25:545-580. CrossRef Medline 
Sommer MA, Wurtz RH (1998) Frontal eye field neurons orthodromically activated from the superior colliculus. J Neurophysiol 80:3331-3335. Medline

Stanford TR, Freedman EG, Sparks DL (1996) Site and parameters of microstimulation: evidence for independent effects on the properties of saccades evoked from the primate superior colliculus. J Neurophysiol 76: 3360-3381. Medline

Stanton GB, Bruce CJ, Goldberg ME (1993) Topography of projections to the frontal lobe from the macaque frontal eye fields. J Comp Neurol 330:286-301. CrossRef Medline

Szabadi E (2012) Modulation of physiological reflexes by pain: role of the locus coeruleus. Front Integr Neurosci 6:94. Medline

Tehovnik EJ, Sommer MA (1997) Electrically evoked saccades from the dorsomedial frontal cortex and frontal eye fields: a parametric evaluation reveals differences between areas. Exp Brain Res 117:369-378. CrossRef Medline

Varazzani C, San-Galli A, Gilardeau S, Bouret S (2015) Noradrenaline and dopamine neurons in the reward/effort trade-off: a direct electrophysiological comparison in behaving monkeys. J Neurosci 35:7866-7877. CrossRef Medline

Vogt BA, Hof PR, Friedman DP, Sikes RW, Vogt LJ (2008) Norepinephri- nergic afferents and cytology of the macaque monkey midline, mediodorsal, and intralaminar thalamic nuclei. Brain Struct Funct 212:465-479. CrossRef Medline

Wang CA, Munoz DP (2014) Modulation of stimulus contrast on the human pupil orienting response. Eur J Neurosci 40:2822-2832. CrossRef Medline

Wang CA, Munoz DP (2015) A circuit for pupil orienting responses: implications for cognitive modulation of pupil size. Curr Opin Neurobiol 33: 134-140. CrossRef Medline

Wang CA, Boehnke SE, White BJ, Munoz DP (2012) Microstimulation of the monkey superior colliculus induces pupil dilation without evoking saccades. J Neurosci 32:3629-3636. CrossRef Medline

Wang CA, Boehnke SE, Itti L, Munoz DP (2014) Transient pupil response is modulated by contrast-based saliency. J Neurosci 34:408-417. CrossRef Medline

Wang CA, Brien DC, Munoz DP (2015) Pupil size reveals preparatory processes in the generation of pro-saccades and anti-saccades. Eur J Neurosci 41:1102-1110. CrossRef Medline

Wang Y, Matsuzaka Y, Shima K, Tanji J (2004) Cingulate cortical cells projecting to monkey frontal eye field and primary motor cortex. Neuroreport 15:1559-1563. CrossRef Medline 